\title{
Perfil do gestor da informação em bibliotecas universitárias na Região Metropolitana do Recife
}

\author{
Anielma Maria Marques Rodrigues \\ Alexander Willian Azevedo \\ Universidade Federal de Pernambuco - UFPE, Brasil
}

ARTIGOS / ARTICLE

\section{Resumo}

Objetivo. Trata-se de uma pesquisa bibliográfica de natureza descritiva com o objetivo de delinear o perfil do gestor da informação em bibliotecas universitárias do Recife e de sua Região Metropolitana.

Método. Para alcançar o objetivo proposto foi realizado um levantamento bibliográfico, na área de ciência da informação, na qual foi possível contextualizar os atributos de competências dos profissionais da informação partir das abordagens qualitativas e quantitativas.

Resultados. Os resultados obtidos apontam questões sobre: a) atividades executadas na rotina do profissional; b) habilidades que possuem para realizar suas tarefas; c) profissional; d) local de trabalho; e) formação acadêmica.

Conclusões. Com as respostas obtidas é possível vislumbrar as diferentes competências do bibliotecário de acordo com sua atuação profissional e experiência pessoal.

Palavras-chave

Bibliotecas universitárias ; Perfil profissional ; Competências ; Bibliotecários universitários ; Recife ; Brasil

\section{Information manager profile in university libraries from the Metropolitan Region of Recife}

\section{Abstract}

Objective. It is a literature of descriptive nature in order to define the profile of the manager of information in university libraries of Recife and its metropolitan area.

Method. To achieve the proposed objective was based on a literature in the area of information science, in which it was possible to contextualize the attributes skills of information professionals from qualitative and quantitative approaches.

Results. Results indicate issues: a) activities performed in the routine of professional b) skills that have to do their jobs, c) professional d) workplace e) academic.

Conclusions. With the responses is possible to discern the different skills of the librarian in accordance with their professional and personal experience.

Keywords

University libraries; Professional profile, Skills, University librarian ; Recife ; Brasil

\section{Introdução}

O mercado de trabalho está cada vez mais competitivo em todas as áreas de atuação, inclusive na área de gestão da informação. A biblioteca que antes era vista como local de trabalho tecnicista com atividades voltadas apenas 
para o tratamento da informação passa a assumir sua função social adaptando-se às novas exigências da chamada sociedade da informação.

Neste cenário o profissional da informação bibliotecário exerce, entre suas diversas atribuições, o papel de disseminador da informação utilizando as novas tecnologias da informação e comunicação (TIC) e outros suportes informacionais existentes, visando suprir as necessidades de seus usuários.

O bibliotecário da atualidade precisa possuir um perfil inovador impulsionado pelas transformações ocorridas continuamente na sociedade da informação, buscando um aperfeiçoamento de seus conhecimentos, dando continuidade a sua formação acadêmica adquirindo novos conhecimentos e atualizando os existentes.

Neste contexto que objetivo do estudo buscou analisar atuação do profissional da informação nas bibliotecas das instituições de ensino superior, públicas e privadas da Região Metropolitana do Recife (RMC), além de verificar quais as exigências e oportunidades demandadas pelo mercado de trabalho a partir apontamento das principais competências desenvolvidas por este profissional.

Portanto, apresenta-se nesta pesquisa o conjunto de conhecimento, habilidades e atitudes que o bibliotecário necessita possuir para desempenhar suas atividades de forma satisfatória, considerando que não se almejou traçar um modelo de perfil "ideal" para bibliotecários por considerar que formação deste profissional no Brasil é generalista com caracteriza marcante no contexto da ambiência em que atue.

\section{Profissionais da informação: Conceitos, propósitos e importância}

Atualmente muito se fala em informação e sobre quem são os profissionais da informação. Bibliotecários, documentalistas, museólogos, arquivistas, analistas, entre outros, são considerados peças-chave nas organizações em que trabalham, pois agregam valores à informação e esta passa a ser tratada como um ativo oferecendo subsídios para a tomada de decisão, contribuindo para melhoramento das atividades propostas pela instituição.

A expressão "profissional da informação" está agregada à chamada sociedade da informação ou sociedade do conhecimento que segundo Targino (2000), caracteriza-se pelo destaque dado à informação e ao seu acesso, além de estar ligada ao setor quaternário da economia com principal característica de possibilidade acesso e utilização da informação e conhecimento.

Com os avanços das tecnologias existentes e com o aumento da produção da informação, necessitou o surgimento de profissionais que possuíssem perfis inovadores (DINIZ; PENA; GONÇALVES, 2011). O profissional da informação surge visando atender à necessidade de buscar, armazenar, controlar, disseminar e compartilhar as informações produzidas nas organizações.

Santos (1996) e Targino (2000) entendem que os profissionais da informação são todos aqueles que fazem da informação o seu objeto de trabalho, agregando os bibliotecários, arquivistas, museólogos, administradores, analistas de sistema, contadores, sociólogos, educadores, publicitários, estatísticos, engenheiros de sistemas, comunicadores, documentalistas, além dos profissionais ligados à informática, à tecnologia da informação e à telecomunicação.

O trabalho do profissional da informação deve configurar como tarefa de mediação, de interfaciamento, de filtragem, de elo de ligação no processo de apropriação de novos conhecimentos, requerendo qualificações diferenciadas e em constante evolução. (ODDONE, 1998.)

Várias organizações têm buscado estes profissionais com a finalidade de aprimorarem seus produtos e serviços. Com isso, estes profissionais precisam possuir competências para atuar na sociedade do conhecimento além de adquirir novas competências com a finalidade de aprimorar suas habilidades e desempenhar melhor seu papel ocupando, com isso, novos nichos de mercado. 
O bibliotecário contemporâneo é o profissional que tem como objeto de estudo e trabalho a informação para fins de disponibilizar aos usuários, independente do suporte que esteja, portanto, o bibliotecário pode ser entendido como mediador entre o usuário e a informação.

Suas atividades são voltadas para o gerenciamento da informação, organização, seleção, aquisição, armazenamento, circulação, desenvolvimento de coleções, entre outras. O papel do bibliotecário na sociedade vem se modificando devido à implantação de novas ferramentas de controle, organização e disseminação da informação. O usuário passa a ser o foco principal de suas atividades e não mais o acervo, ao mesmo tempo em que a disseminação passa a ter mais importância que a preservação da informação. (ROCHO, 2007).

O mercado de trabalho demanda que o bibliotecário tenha uma educação continuada para que possa desenvolver suas habilidades, seja através de cursos de especialização, de participação em congressos, palestras, grupos de discussão entre outras fontes de aperfeiçoamento profissional.

\subsection{Competências do gestor da informação}

Atualmente, o mercado de trabalho está cada vez mais exigente com os profissionais. Não basta apenas ter uma graduação para ser contratado com um bom salário e cargo. Além da graduação, as instituições exigem competências que possam unir-se à sua formação profissional.

Amaral (2010) afirma que as competências são formadas por aspectos intelectuais, emocionais e morais, sendo todos importantes para o desempenho adequado das funções nas quais o profissional é dito competente. Esta definição indica três dimensões para competência: o "saber" que é o conhecimento adquirido, o "saber faze"r que são as habilidades e o "saber ser" que são as atitudes.

A competência, segundo Fleury e Fleury (2001) é um saber agir responsável e reconhecido, que implica mobilizar, integrar, transferir conhecimentos, recursos e habilidades, que agreguem valor econômico à organização e valor social ao indivíduo. Portanto, pode-se entender que a competência é a união do conhecimento, habilidades e,atitudes que o profissional, de qualquer área, espera possuir.

O profissional da informação está inserido no mercado de trabalho em constante mutação e precisa possuir conhecimentos de várias áreas e aplicá-los às suas atividades do dia-a-dia procurando aperfeiçoá-las e executá-las do melhor modo possível. No contexto social atual o profissional da informação deve possuir capacidade de aprendizagem e adaptação às mudanças, deve saber trabalhar em equipes multidisciplinares, e ser alfabetizado digitalmente (BELLUZZO, 2011).

O bibliotecário, procura cada vez mais, a educação continuada para adquirir conhecimentos e atualizar-se profissionalmente. Contudo, não há um perfil pré-moldado por competências específicas que este profissional deve seguir, seu perfil é desenvolvido de acordo com suas preferências e afinidades.

\section{Procedimento metodológico}

O método empregado neste estudo configura-se como uma pesquisa bibliográfica de natureza qualitativa e quantitativa, na qual foi possível compreender o universo estudado através das perguntas feitas aos bibliotecários que atuam em instituição de ensino superior da RMR.

O universo da pesquisa foi composto por bibliotecários atuantes em instituições de ensino superior, públicas e privadas, da Região Metropolitana do Recife que compreende as cidades: Olinda; Paulista; Cabo de Santo Agostinho; Ipojuca; Jaboatão dos Guararapes; Moreno; Araçoiaba; Igarassu; Goiana; Abreu e Lima; Camaragibe; Itamaracá; São Lourenço da Mata e Itapissuma.

De acordo com o site do e-MEC, fazem parte deste universo, 61 IES públicas e privadas que possuem cursos em modalidade presencial, considerando que a maioria dessas instituições estão localizadas em Recife, $61 \%$, seguido por Olinda, $15 \%$, e por Jaboatão dos Guararapes, $6 \%$. Segundo o site do e-MEC, os municípios de Moreno, 
Araçoiaba, Abreu e Lima, Camaragibe, Itapissuma e Itamaracá não possuem faculdades que ministrem aula em modalidade presencial.

Os dados foram coletados através ferramenta Google Docs $\AA_{\text {, na }}$ nual foram obtidos 42 questionários respondidos que representa $68,8 \%$ do total das instituições do universo escolhido. Esse montante foi suficiente para termos uma amostragem significativa do estudo.

\section{Discussão dos resultados}

A análise e os resultados dos dados foram desenvolvidos com base nas questões expostas no questionário que foi enviado para participantes do estudo.

Com base na tabulação dos dados coletados, as tabelas e gráficos a seguir expõem a reunião dos resultados impetrados com a aplicação do questionário. As respostas permitiram o conhecimento de informações relevantes em que os percentuais obtidos traduzem o perfil dos gestores de informação das bibliotecas universitárias da RMR. As questões foram divididas em grupos conforme o assunto. São elas: (1) Dados pessoais, (2) Formação, (3) Trabalho e (4) Perfil profissional.

$\mathrm{Na}$ primeira atribuição discutida, observou-se que $81 \%$ dos profissionais da informação bibliotecário que responderam o questionário foram do sexo feminino e apresentou a faixa etária de 26 a 30 anos.

Já a formação acadêmica dos profissionais, 40\% dos entrevistados apontaram ter especialização na modalidade lato sensu. Este resultado demonstra que o profissional bibliotecário atuante nas IES na RMR tem procurado especializar-se, "tendo em vista, que atualmente o mercado de trabalho requer profissionais mais qualificados e capacitados diante da globalização e dos avanços tecnológicos” (MIRANDA e SOLINO, 2006, p. 391).

Em relação ao tempo de formação, foi possível observar que a maioria dos entrevistados (48\%) tem sua formação recente, entre 1 e 5 anos. Na questão de conhecimento em idioma estrangeiro, 69\% dos bibliotecários afirmaram possuir conhecimento em pelo menos um idioma estrangeiro. O principal idioma mencionado foi o inglês, seguido pelo espanhol e francês.

A pesquisa também procurou observar às atualizações profissionais, de acordo com resultados obtidos os bibliotecários afirmaram estar em constante busca por atualizações, através dos mecanismos de leitura de livros, artigos científicos, blogs, entre outros.

Nas questões sobre a rotina do profissional da informação no escopo do mercado de trabalho existente na Região Metropolitana do Recife, foi possível observar na requisito de cargo que ocupa na organização, como se tratou de uma pergunta aberta, vários termos foram indicados, entre eles: bibliotecário, bibliotecário gestor, assistente de biblioteca, bibliotecária de expansão, auxiliar de biblioteca, gestor, bibliotecário documentalista, gerente de biblioteca, bibliotecário chefe, coordenador de biblioteca, chefia, técnico administrativo.

Em relação à localização da instituição de ensino superior que o profissional atual, aproximadamente $80 \%$ está localizado na cidade do Recife.

Referente ao tipo de instituição que o bibliotecário atua foi notado que, apesar do aumento do número de concursos públicos para a área de biblioteconomia, a rede privada de ensino superior apresenta maior concentração de contratação dos profissionais formados na RMR com $71 \%$.

A faixa salarial do bibliotecário atuante na RMR está entre 3 a 4 salários mínimos, levando em consideração o salário mínimo atual, esse profissional recebe entre $R \$ 1.200,00$ a $R \$ 2.400,00$. A principal exigência feita pelas instituições para sua contratação é possuir curso de graduação em biblioteconomia em conformidade a legislação, em segundo lugar, o conhecimentos em informática e por ultimo curso de especialização.

No que diz a respeito dos incentivos que a instituição ensino superior publico proporciona a seus colaboradores para capacitar-se e/ou atualizar-se profissionalmente (55\%) respondentes indicaram que as instituições não oferecem 
incentivo, enquanto demais (45\%) ofertam apoio de diárias para participação em eventos, licença para frequentar cursos em outro estado, plano de cargos e carreiras, convênios com outras instituições,

As instituições privadas também oferecem alguns incentivos, mas estes ficam restritos a bolsas de estudos totais ou parciais nos cursos de graduação e pós-graduação oferecidos na própria instituição, redução da carga horária de trabalho caso o colaborador esteja participando de algum evento ou frequentando algum curso.

De maneira a complementar a questão anterior, perguntou-se os motivos e/ou benefícios oferecidos pela instituição que levou a profissional a optar por ela. O principal resultado obtido foi experiência profissional, em seguida, o desemprego que não permite esperar e escolher entre uma ou outra instituição que lhe ofereça maiores benefícios. A estabilidade foi observada principalmente nas instituições públicas que oferece uma maior segurança trabalhista ao profissional.

A questão relacionada às atividades que o bibliotecário exerce em seu local de trabalho, a Figura 1 exemplifica as opções com suas respectivas respostas:

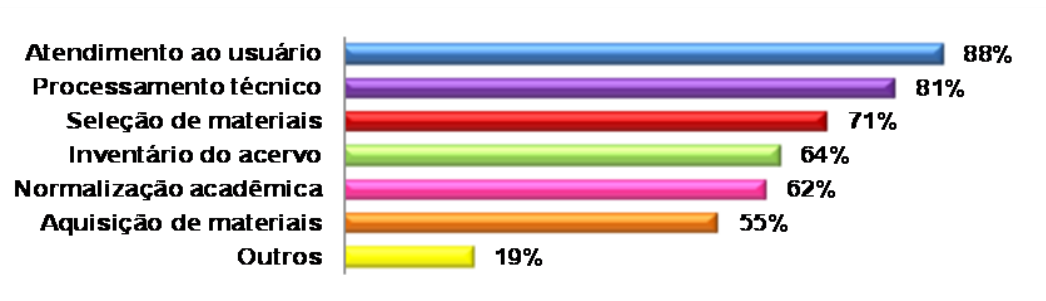

Figura 1: Atividades que o bibliotecário exerce no local de trabalho.

Portanto, os resultados esboçados na Figura 1 sugere que os bibliotecários exercem todas as funções dentro da unidade de informação. São considerados multiprofissionais, que conseguem desempenhar várias atividades quase que simultaneamente.

Para conhecer as competências adquiridas e desenvolvidas pelos profissionais, elaboramos um quadro, na qual estavam dispostas algumas competências julgadas importantes na rotina do trabalho em bibliotecas universitárias.

O primeiro ponto respondido foi quanto à capacidade de elaborar, desenvolver e coordenar projetos de informação que estejam ligados a qualquer área de informação em bibliotecas universitárias. 33\% dos bibliotecários afirmaram ter esta habilidade, que permite desenvolver projetos que promovam um melhor funcionamento e um maior entendimento das atividades promovidas pela biblioteca.

A segunda afirmação esteve relacionada à utilização de técnicas de marketing para divulgação dos serviços prestados à biblioteca, consideração a promoção, uma dos elementos que constitui os 4P do marketing (produto, preço, praça e promoção) abrange o uso de canais de comunicação para informar a existência de algo, além de convencer os possíveis interessados em usar ou adquirir aquilo que se promove." (AMARAL, 2011, p. 76). Nesta questão os bibliotecários, novamente, afirmaram ter esta habilidade.

Relativo à capacitação e orientação de usuários para utilizar os serviços e recursos das unidades de informação, a Figura 2 corrobora com visão de Ronchesel e Pacheco (2008) quando apresenta 45\% dos respondentes apontando que estabelecimento de diretrizes informacionais para capacitar usuários de bibliotecas universitárias é de fundamental importância para atingir seus objetivos. 


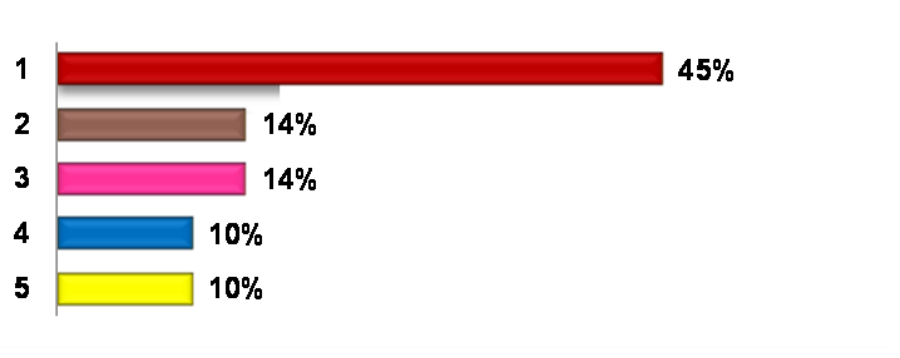

Figura 2: Capacitação e orientação de usuários para utilizar os serviços e recursos das unidades de informação.

A pesquisa demonstrou que (29\%) bibliotecários realizam planejamento e execução de estudos de usuários, que segundo Lucas (et al, 2008, p. 63) "[...] estudo de usuários é uma investigação feita para identificar e caracterizar os interesses, as necessidades e os hábitos de uso de informação dos usuários reais e/ou potenciais de um sistema de informação".

Também foi possível observar que 38\%, dos bibliotecários respondente tem habilidade de realizar o processamento técnico (classificação, catalogação, indexação) de diferentes documentos e suportes, visto que esta atividade de suma importância para promover a recuperação da informação de forma eficiente e eficaz.

Para a questão sobre bibliotecário insere ou atualiza as informações contidas em sites ou portais, $26 \%$ dos bibliotecários universitários afirmou não ter habilidade com esta atividade, onde podemos concluir que ainda haja resistência, em algumas bibliotecas da RMR, para a adoção das novas tecnologias e divulgação dos serviços em meio online.

Verificar a satisfação dos usuários assemelha-se a questão do estudo de usuários, contudo, ao analisar esta questão requer que sejam feitas melhorias a fim de garantir uma melhor qualidade na prestação dos serviços. " $A$ satisfação das pessoas, diante da concretização de suas necessidades informacionais, pode inferir no sucesso/continuidade das organizações ou no seu contrário." (COSTA; RAMALHO, 2010). Neste ponto, 40\% bibliotecários detêm habilidades para realizar esta tarefa.

No questionamento sobre as práticas de seleção de materiais e realização de inventário do acervo, 33\% dos profissionais responderam que possuem esta competência.

Outro ponto questionado foi a capacidade de buscar informações em diversas fontes e tratá-la de acordo com o interesse dos usuários, onde $31 \%$ dos bibliotecários universitários atuantes na RMR do Recife assinalaram ter esta habilidade, que versa com Lucas e Souza (2007), quando afirmam que informações personalizadas de acordo com seu perfil e sua linha de pesquisa aprimorando os serviços oferecidos pela biblioteca.

Referente a habilidade de realizar técnicas de conservação e/ou recuperação do acervo, a maioria dos bibliotecários universitários (31\%) afirmou não possuir esta habilidade, na qual deduzimos que esta atividade seja de competência de restauradores que detém estas técnicas.

Por fim, foi perguntado se o profissional que havia respondido as perguntas sentia-se realizado profissionalmente, $69 \%$ responderam que sentem realizados profissionalmente e $31 \%$ responderam que não. As principais insatisfações apontadas pelos bibliotecários foram: em relação à remuneração; a falta de reconhecimento da profissão; falta de oportunidade de crescimento profissional; falta de estímulo; o fato de exercer funções de auxiliar ou assistente; falta de preparação na universidade para o mercado de trabalho; falta de comprometimento dos órgãos de classe responsáveis; entre outras. 


\section{Considerações Finais}

Nesta pesquisa foi possível visualizar as principais características do perfil do bibliotecário, que atualmente é visto como gestor da informação, atuante nas instituições de ensino superior da cidade do Recife e região metropolitana.

Com base no instrumento de pesquisa que foi disponibilizado de forma online, questões foram levantadas e respondidas por profissionais que atuam em bibliotecas universitárias e se dispuseram a colaborar com o presente estudo.

Diversas observações puderam e poderão ser feitas baseadas nas respostas obtidas. Os profissionais afirmaram possuir grande parte das competências e habilidades propostas pelo instrumento de estudo, o que demonstra que o profissional atuante no mercado de trabalho deve estar em constante atualização para desempenhar as funções exigidas, nos setores das bibliotecas universitárias tendo sempre como foco principal seu cliente que são, em sua maioria, professores, pesquisadores, alunos e, em alguns casos, a comunidade em geral, promovendo o compartilhamento da informação.

O que se observa é que as bibliotecas universitárias possuem um profissional multifuncional, que consegue abranger diversas funções e executá-las. Estes multiprofissionais buscam sempre atualizar-se profissionalmente para que suas atividades meios e fins tenham qualidade e atinjam os objetivos para que elas foram denominadas.

É de suma importância o profissional da informação, denominado nesta pesquisa como bibliotecário universitário, ter conhecimento de suas habilidades e competências, para que possa aprimorá-las e adquirir novas competências somando às existentes para que dessa forma seja possível se destacar no mercado competitivo da gestão da informação.

\section{Referências}

AMARAL, Roniberto Morato do. Análise dos perfis de atuação profissional e de competências relativas à inteligência competitiva. 2010. 234 f. Tese (Doutorado em Engenharia de Produção) - Universidade Federal de São Carlos, São Paulo, 2010. Disponível em: < http://www.bdtd.ufscar.br/htdocs/tedeSimplificado//tde arquivos/1/TDE-2010-05-12T123334Z3008/Publico/2950.pdf> Acesso em 22 jun. 2012.

AMARAL, Sueli Angelica do. Atividades de marketing na promoção de serviços de informação: pesquisa sobre o SONAR-INIS e o SERVIR-INIS do CIN/CNEN. Perspectivas em Ciência da Informação, v.6, n.1, p. 75-96, jan./jul. 2011. Disponível em: < http://portaldeperiodicos.eci.ufmg.br/index.php/pci/article/view/438/248> Acesso em: 30 jul. 2012.

BELLUZZO, Regina Célia Baptista. As competências do profissional da informação nas organizações contemporâneas. Revista Brasileira de Biblioteconomia e Documentação. São Paulo, v.7, n.1, p. 58-73, jan. - jun. 2011. Disponível em: < http:// rbbd.febab.org.br/rbbd/article/download/180/186> Acesso em 08 maio 2012.

COSTA, Luciana Ferreira da; RAMALHO, Francisca Arruda. Novas perspectivas dos estudos de satisfação de usuários. Encontros bibli: revista eletrônica de biblioteconomia e ciência da informação, Florianópolis, v. 15, n. 30, p. 57-73, 2010. Disponível em:< http://www.periodicos.ufsc.br/index.php/eb/article/view/11211/19530 > Acesso em: 30 jul. 2012.

DINIZ, Edileuda Soares; PENA, André; GONÇALVES, Leandro Damaceno. O perfil do profissional da informação demandado por uma empresa do ramo jornalístico: um estudo de caso. Revista ACB, Florianópolis, v. 16, n. 1, p. 289 - 307, jan./jul., 2011. Disponível em: < http://revista.acbsc.org.br/index.php/racb/article/view/745/pdf 51> Acesso em: 08 jul. 2012.

FLEURY, Maria Tereza Leme; FLEURY, Afonso. Construindo o conceito de competência. Revista de Administração Contemporânea, Curitiba, v. 5, n. esp., p. 183 - 196, 2001. Disponível em: < http://www.scielo.br/pdf/rac/v5nspe/v5nspea10> Acesso em: 08 maio 2012.

LUCAS, André. et al. Estudo de usuário como estratégia para gestão da informação e do conhecimento : um estudo de caso. Revista ACB, v. 13, n. 1, p. 59-79, jan./jun., 2008. Disponível em: $\leq$ http://revista.acbsc.org.br/index.php/racb/article/view/521/658> Acesso em: 30 jul. 2012.

LUCAS, Elaine R. de Oliveira; SOUZA, Nicole Amboni de. Disseminação seletiva da informação em bibliotecas universitárias sob o prisma do customer relationship managment. Informação \& Informação, Londrina, v. 12, n.1. jan./jul, 2007. Disponível em: < http://www.uel.br/revistas/uel/index.php/informacao/article/view/1745> Acesso em: 30 jul. 2012. 
MIRANDA, Ana Cláudia Carvalho de; SOLINO, Antônia da Silva. Educação continuada e mercado de trabalho: um estudo sobre bibliotecários do Estado Rio Grande do Norte. Perspectivas em Ciência da Informação, Belo Horizonte, v. 11, n. 3, p. 383 - 397 , set/dez. 2006. Disponível em: <http://www.scielo.br/pdf/pci/v11n3/a07v11n3.pdf>

ODDONE, N. O profissional da informação e a mediação de processos cognitivos: a nova face de um antigo personagem. Informação \& Sociedade, João Pessoa, v. 8, n.1, 1998. Disponível em: <

http://dci2.ccsa.ufpb.br:8080/ispui/bitstream/123456789/320/1/v8 n1 1998 2.pdf> Acesso em: 06 maio 2012.

ROCHO, Rodolfo de Matos. O estereótipo do bibliotecário no cinema. 2007. 98 f. Monografia (Bacharelado em Biblioteconomia) - Universidade Federal do Rio Grande do Sul, Porto Alegre, 2007. Disponível em: <

http://www.lume.ufrgs.br/bitstream/handle/10183/16257/000667029.pdf?sequence=1 > Acesso em: 08 maio 2012

RONCHESEL, Maria Helena Souza; PACHECO, Leandro Kingeski. Diretrizes para cursos a distância de capacitação de usuários em bibliotecas universitárias. Revista Brasileira de Biblioteconomia e Documentação, São Paulo, v.4, n.2, p. 33-42, jul./dez., 2008. Disponível em: < http://www.brapci.ufpr.br/documento.php?dd0=0000006197\&dd1=61230>Acesso em 29 jul. 2012.

SANTOS, Jussara Pereira. O moderno profissional da informação: o bibliotecário e seu papel face aos novos tempos. Informação \& Informação, Londrina, v.1, n.1, p. 5-13, jan./jun., 1996. Disponível em:

<http://www.uel.br/revistas/uel/index.php/informacao/article/view/1613/1367> Acesso em: 06 maio 2012.

TARGINO, Maria das Graças. Quem é o profissional da informação? Transinformação, São Paulo, v. 12, n. 2, p.61-69, jul./dez. 2000.

\section{Dados dos autores}

Anielma Maria Marques Rodrigues

Possui graduação em Biblioteconomia pela Universidade Federal de Pernambuco (2007) e especialização em Gestão da Informação em Arquivos pela Faculdade de Ciências Humanas Esuda (2012) . Atualmente é Bibliotecária da Faculdade de Comunicação, Tecnologia e Turismo de Olinda.

anielma@yahoo.com.br

\section{Alexander Willian Azevedo}

Bacharel em Ciência da Informação com habilitação em Biblioteconomia pela Pontifícia Universidade Católica de Campinas. Mestre em Ciência da Informação pelo Programa de Pós-Graduação do Centro de Ciências Humanas e Sociais Aplicadas, PUC-Campinas, Bolsista CAPES. Professor Assistente vinculado ao Departamento de Ciência da Informação da Universidade Federal de Pernambuco (UFPE).

azevedo.aw@gmail.com

Recebido - Received: 2012-12-19

Aceitado - Accepted: 2012-12-30

(c) EY $_{\text {EY }}$ New articles in this journal are licensed under a Creative Commons Attribution 3.0 United States License.

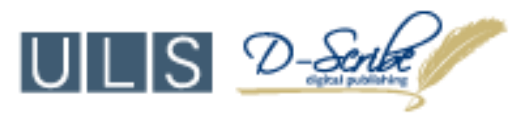

This journal is published by the University Library System of the University of Pittsburgh as part of its D-Scribe Digital Publishing Program and is cosponsored by the University of Pittsburgh Press. 